\title{
Auditory Training Using Remembering the Order of Sentences for the Elderly Who Wear Hearing Aids: Is it Effective for Speech Perception in Noise, Working Memory and Reasoning Ability?
}

\author{
Donghoon Kang ${ }^{1,2}$, So Hyun Kim ${ }^{1,3}$, Dajung Yun ${ }^{1,3}$, Junghwa Bahng ${ }^{1,4}$ \\ 'Department of Audiology and Speech-Language Pathology, Hallym University of Graduate Studies, Seoul, Korea \\ ${ }^{2}$ Starkey Hearing aid GM Center, Seoul, Korea \\ ${ }^{3} \mathrm{GN}$ Hearing Korea, Seoul, Korea \\ ${ }^{4}$ HUGS Center for Hearing and Speech Research, Seoul, Korea
}

Received: March 13, 2020 Revised: April 7, 2020

Accepted: April 9, 2020

\section{Correspondence:} Junghwa Bahng, PhD

Department of Audiology and Speech-Language Pathology, Hallym University of Graduate Studies, 427 Yeoksam-ro, Gangnam-gu, Seoul 06197, Korea

Tel: $+82-70-8680-6933$

Fax: +82-2-3453-6618

E-mail: bahng.jh@hallym.ac.kr
Purpose: The present study examines auditory training outcomes in terms of speech perception in noise, working memory, reasoning ability, and subjective hearing aid satisfaction. Methods: Ten older adults who wear hearing aids (mean age: 71.6) voluntarily participated in the study. For the training material, 78 sentence sets composed of 3 to 5 sentences were used. During the auditory training, participants tried to remember the order of sentences. Among the 78 sentence sets, 45 contained clues and the rest did not. Each participant underwent assessments including speech perception in noise and digit spans and reasoning test and completed a self-report hearing aid satisfaction questionnaire both pre- and post-auditory training. The participants completed eight sessions of the auditory training. Results: The results showed a statistically significant increase in speech recognition ability in noise, short-term memory, and working memory, as well as satisfaction with hearing aid use. Despite a slight increase on the reasoning test, there was no statistically significant improvement. Conclusion: The results of this study suggested that the auditory training in remembering the order of sentences improved speech perception in noise, sensory and working memory, and subjective satisfaction with hearing aids. Future research can investigate more effective auditory training tools to improve the various cognitive skills and communication ability of older adults who wear hearing aids.

Key Words: Auditory training, Cognitive training, Hearing aid satisfaction, Sentence ordering, Working memory.

\section{INTRODUCTION}

세계보건기구(World Health Organization, 2020)에서는 전 세 계의 약 6억 6천6백만 명의 사람들이 청력손실을 겪고 있으며, 2050년까지 약 9억 명 이상이 난청으로 어려움을 겪을 것으로 예 상한다고 보고하였다. 70 세 이상 노인의 $2 / 3$ 정도는 일상생활에 서 의사소통에 영향을 줄 정도의 청력손실이 있으며(Lin, 2011), 노인 인구의 증가로 청력손실이 있는 노인 인구는 앞으로 점차 증가할 전망이다. 청력손실은 의사소통의 저하 발생의 원인이 되 며 이로 인해 가족 간 고립은 물론 사회적 고립, 치매, 우울 등의

(c) This is an Open Access article distributed under the terms of the Creative Commons Attribution Non-Commercial License (https://creativecommons.org/licenses/by-nc/4.0) which permits unrestricted non-commercial use, distribution, and reproduction in any medium, provided the original work is properly cited.
문제가 발생하기도 한다(Mener et al., 2013; Wolfgang, 2019).

청력손실로 인한 부정적 영향을 최소화하는 방법으로는 보 청기의 사용이 가장 보편적이다. 그러나 많은 노인들은 보청기 사용 후에도 여전히 의사소통을 원활히 하지 못하게 되며, 이러 한 현상은 여러 명이 동시에 이야기하는 환경 혹은 소음이 있 는 환경에서 더욱 어려워한다(Pichora-Fuller et al., 1995). 청력 손실과 노화로 인한 중추청각 시스템의 주파수와 시간 처리 기 능의 저하는 보청기의 적절한 적합으로 충분한 소리가 제시됨 에도 불구하고 언어 처리의 어려움의 원인이 되어 원활한 의사 소통을 수행하지 못하게 된다(Roque et al., 2019). 이러한 어려 움을 극복하기 위한 여러 방법으로 많은 시도가 행해졌으며, 여러 방법 중 청능훈련은 청력손실이 있는 노인의 의사소통 증 진을 위한 효과적인 방법임을 많은 연구에서 보고하였다(An- 
derson et al., 2013; Ferguson et al., 2014; Karawani et al., 2016). 청능훈련은 소리에 대한 청감각 증가를 위해 어음을 포 함한 소리를 이용한 듣기의 적극적인 참여를 말하며, 난청인은 체계적으로 제시된 소리를 익혀 소리에 대한 감각을 개선하게 된다(Schow \& Nerbonne, 2006). 이러한 청능훈련은 신경가소 성(neuro-plasticity)을 활용하는 것에 목적이 있다.

신경가소성은 신경 세포, 신경교 세포, 시냅스와 같은 해부학 적 구조의 적응을 일컫는다. 이는 청각적 지각, 기억의 통합 등 지각적 혹은 인지적 자원의 활용을 필요로 하는 활동의 활발한 개입에 따른 생리학적 절차이다(Cai et al., 2014; Tremblay, 2007). 신경가소성은 개인이 훈련을 통해 새로운 지식이나 기술 을 습득하면, 정보는 기존의 신경 경로 및 네트워크를 강화하거 나 새로운 신경 회로 및 시냅스를 생성하여 발생할 수 있다 (Wall et al., 2002). 따라서 청능훈련에 적극적으로 참여하면 노 인을 새로운 자극에 노출시키고 청각 또는 인지 기능을 향상시 켜 뇌의 가소성 변화를 일으킬 수 있다. 청력의 손실과 인지의 저하와의 관계는 많은 연구를 통해 밀접한 관련이 있다는 것이 밝혀졌으며 훈련을 통해서 신경가소성의 원리에 따라 청감각 증가와 의사소통능력의 향상 그리고 인지력도 증가하는 것이 밝혀졌다. 최근의 국외 연구를 살펴보면 보청기 착용 노인을 대 상으로 여러 청능훈련 도구를 이용하여 적극적 훈련을 한 후 작업기억력(Henshaw \& Ferguson, 2013; Krishnamurti et al., 2015), 집행 기능(Sweetow \& Sabes, 2006), 단기기억(Anderson et al., 2013), 집중력(Ferguson et al., 2014) 등의 인지력 검사에 서 유의한 향상을 보이는 것으로 보고하였다.

국내의 다양한 연구에서는 청능훈련을 시행했을 때 단어인 지도, 문장인지도 등 어음의 인지능력뿐만 아니라 소음하 문장 에서의 인지능력이 향상되었음을 보고하였다(Jo et al., 2013; Kim \& Lee, 2010; Kim \& Lee, 2017; Yeo et al., 2014). 인지력
의 증가를 보고한 청능훈련에 관한 연구는 저자가 검색한 범위 안에서는 찾을 수 없었다.

앞의 국내외의 청능훈련에 관한 연구를 참고할 때 집중 듣기 훈련이 어음인지도의 향상은 물론 인지력의 향상에 영향을 끼 치는 것은 분명하다. 국내의 연구에서 사용한 청능훈련 도구를 살펴보면 단순히 어음을 듣고 따라 말하기에 청능훈련 방법의 초점이 맞춰져 있다. 청력손실의 여부와 상관없이 노화로 인하 여 많은 노인들은 소음이 있는 환경에서의 의사소통의 어려움 을 호소한다. 이러한 소음하 의사소통의 어려움은 노화로 인한 인지능력의 감소와 깊은 연관이 있다(Nuesse et al., 2018). 이러 한 청각감을 이용하여 기억, 추론, 이해 등의 인지능력 향상에 도움을 주는 활동을 포함한 훈련을 실시할 수 있다면 청력손실 이 있는 노인에게 인지능력 향상과 함께 소음하 의사소통능력 의 향상을 기대할 수 있을 것이다.

본 연구의 목적은 다음과 같다. 기존에 실시하였던 청능훈련 의 방법은 소음하 의사소통능력의 향상을 이끌었음은 분명하 다. 본 연구에서는 청력손실을 가진 노인을 대상으로 기존의 방법보다 인지적 조작이 필요한 방법으로 훈련을 실시하여 인 지능력 중 작업기억력과 추론능력의 향상과 소음하 인지능력 의 향상을 보고자 하였다. 훈련의 방법으로 한 문장을 듣고 따 라 말하는 것이 아닌 여러 개의 문장을 듣고 이해하고 기억하 여 어그러진 문장을 순서화하는 방법으로 듣기 능력뿐만 아니 라 인지적 조작능력까지 향상할 수 있는 훈련 방법을 고안하였 고 이를 보청기 착용 노인을 대상으로 실시하고자 한다.

\section{MATERIALS AND METHODS}

\section{연구 대상}

청능훈련 효과를 확인하기 위해 보청기를 착용하고 있는 난

Table 1. Demographic information of subjects

\begin{tabular}{ccccccccc}
\hline Subjects & Age (years) & Gender & $\begin{array}{c}\text { HA experience } \\
\text { (months) }\end{array}$ & $\begin{array}{c}\text { Daily use of HA } \\
\text { (hours) }\end{array}$ & HA ear & $\begin{array}{c}\text { PTA } \\
\text { (right, dB HL) }\end{array}$ & $\begin{array}{c}\text { PTA } \\
\text { (left, dB HL) }\end{array}$ & WRS (\%) \\
\hline 1 & 66 & F & 11 & 10 & Left & 36.6 & 41.6 & 76.0 \\
2 & 82 & F & 68 & 9 & Right & 56.6 & 56.6 & 16.0 \\
3 & 61 & F & 64 & 14 & Right & 48.3 & 53.3 & 40.0 \\
4 & 71 & M & 16 & 8 & Both & 86.6 & 50.0 & 28.0 \\
5 & 72 & F & 16 & 12 & Right & 48.3 & 46.6 & 44.0 \\
6 & 68 & M & 8 & 9 & Both & 50.0 & 6.6 & 84.0 \\
7 & 70 & M & 10 & 7 & Both & 56.6 & 21.6 & 88.0 \\
8 & 70 & M & 12 & 8 & Both & 58.3 & 53.3 & 36.0 \\
9 & 72 & M & 13 & 6 & Both & 46.6 & 80.0 & 32.0 \\
10 & 85 & F & 72 & 14 & Both & 50.0 & 61.6 & 40.0 \\
Mean & 71.7 & & 29 & 9.7 & & 53.8 & 47.1 & 48.4 \\
\hline
\end{tabular}

HA: hearing aid, PTA: pure tone average, WRS: word recognition score, F: female, M: male 
청인 총 10 명을 대상으로 하였다. 모두 60 세 이상 10 개월 이상 보청기를 착용하는 자를 대상으로 하였다. 참여 대상자는 모두 간이치매검사(Korean mini-mental state exam) (Kang et al., 1997)의 질문을 통해 인지 기능에 문제가 없음을 확인하였다. 연구 참여 대상자 10 명의 연령, 성별, 보청기 착용 기간 및 하루 사용 시간, 보청기 착용 귀 등에 대한 정보는 Table 1에 제시하 였다. 연구 참여 대상자의 평균 나이는 71.7세(범위: 61 85세, 표 준편차: 7.07)이며, 하루에 보청기를 착용하는 시간은 평균 9.7 시간(표준편차: 2.79)이었다. 또한 보청기를 착용한 후의 오른 쪽 평균 pure tone average (PTA)는 $53.8 \mathrm{~dB} \mathrm{HL}$, 왼쪽 PTA는 $47.1 \mathrm{~dB}$ HL이었다. 좋은 쪽 word recognition score (WRS)의 평균은 48.4\%(범위: 16 88\%)였다. 난청의 형태는 골도와 기도 의 역치 차가 $10 \mathrm{~dB} \mathrm{HL}$ 미만인 감각신경성 난청이다. 모두 보 청기 착용 후 적절한 만족감을 나타내고 있었고 훈련을 실시하 기 전 연구의 목적과 절차에 대한 설명을 모두 이해하고 실험 참여에 대한 동의서를 작성하였다.

\section{연구 재료}

\section{훈련에 사용한 문장}

문장 순서화 훈련 도구는 단서가 있는 문장으로 구성한 이야 기와 단서가 없는 문장으로 구성된 이야기로 총 195세트를 구 성하였다(Table 2). 이야기의 내용은 단서가 있어 비교적 순서 화하기 쉬운 이야기와 단서 없이 나열식으로 구성된 이야기로 구성하였다. 단서가 있는 이야기는 원인과 결과가 분명하거나, 아침, 점심, 저녁 등의 시간 순서가 분명한 이야기 등으로 구성 하였다. 단서가 없는 이야기는 그림 묘사하기, 스포츠 게임 룰, 인물에 대한 묘사 등의 순서가 바뀌어도 크게 문제가 되지 않 는 문장으로 구성하였다. 한 이야기당 3 5개의 문장으로 구성 되어 있으며 이야기는 포털 사이트, 교양 도서 등에서 자료를 수집하였다.

\section{이야기 목록 음원 제작}

수집한 문장의 음원 녹음을 위해 한국어 표준말을 사용하 는 성인 여성 1명이 발화하여 녹음하였다. 녹음을 위해 AT407 마이크(Audio-Technica, Tokyo, Japan), TLM102(Neumann,

Table 2. Classification according to the presence of clues

\begin{tabular}{lc}
\hline Classification & Number \\
\hline With clues & \\
Time-ordered & 35 \\
Cause and effect & 10 \\
Without clues & \\
Description & 8 \\
List & 23 \\
\hline
\end{tabular}

Berlin, Germany)를 사용하였다. 녹음된 음원 데이터는 Adobe Audition version 3.0(Adobe, San Francisco, CA, USA)을 사용하여 각 음원의 root mean squares (RMS) 강도가 동일하 도록 조절하였다. 또한 소음하 청능훈련을 위해 Adobe Audition version 3.0 프로그램을 사용하여 각 음원의 RMS는 $25 \mathrm{~dB}$, 앞뒤 휴지 간격은 $500 \mathrm{msec}$ 로 조절하였다. 문장은 표준어를 구 사하는 여자 성우가 녹음하였으며 녹음 시 난청 노인이 인지하 기 어렵지 않은 적절한 속도를 유지할 수 있도록 하였다.

\section{연구 장비 및 검사 조건}

검사에 사용한 청력 측정 장비는 보정을 실시한 청력 검사기 (AD629, Interacoustics A/S, Assens, Denmark)로 실시하였 고, 청능훈련은 소음 수준이 $40 \mathrm{dBA}$ 이하의 훈련실에서 외부 스피커(loudspeaker; BR-1000A Plus, Britz, Paju, Korea)를 대 상자의 귀와 동일한 높이에서 $1 \mathrm{~m}$ 의 거리에 위치한 후 정면 $\left(0^{\circ}\right)$ 에서 실시하였다. 배경소음은 백색잡음을 사용하였으며 MP4 파일로 저장하여 외부 스피커(loudspeaker; BR-1000A Plus) 에 연결한 상태로 signal-to-noise ratio (SNR)를 조절하여 검 사기를 통해 제시하였다.

\section{연구 절차}

다음의 평가를 총 2 회, 훈련 시작 전과 훈련이 끝난 직후인 10 주 후에 동일하게 시행하였다.

\section{소음하 어음 평가}

훈련의 효과를 평가하기 위하여 기본적인 PTA, WRS 이외 에 Korean matrix test (Kim \& Lee, 2018)를 이용하여 조용한 상황과 소음하 상황(10 dB SNR, $5 \mathrm{~dB}$ SNR)에서 측정하였다. 소음하 검사는 앞에 제시한 바와 같이 $1 \mathrm{~m}$ 거리에 위치하고 $0^{\circ}$ 에 위치하여 검사하였다. 문장 제시 레벨은 참여자가 보청기를 착용하고 잘 들을 수 있는 수준을 설정하여 제시하였다.

\section{인지기능검사}

\section{작업기억력검사}

단기기억 및 작업기억력 검사(Sung, 2011)로 숫자폭(digit span)검사와 단어폭(word span)검사를 각각 24문항씩 실시했 다. 24 문항 중 12 문항은 짧은 시간 동안 정보를 유지할 수 있는 능력을 평가하는 바로따라말하기검사를, 나머지 12 문항은 그 숫자를 기억하는 것과 동시에 역순으로 정보를 조작해야 하는 작업기억 과제인 거꾸로따라말하기검사를 실시했다. 숫자 바로 따라말하기검사는 단기간 기억하는 저장능력에 중점을 둔 단 기기억 과제로, 숫자 거꾸로따라말하기검사는 숫자를 기억하는 
것과 동시에 역순으로 정보를 조작해야 하므로 작업기억 과제 로 분류될 수 있다.

추론능력검사

추론능력검사는 Cognitive-pragmatic language Ability assessment Protocol for Traumatic Brain Injury (CAPTBI) (Lee, 2013)를 사용하여 실시하였다. 총 16점으로 이루어져 있으며, 주 의력 평가 8점과 추론력 평가 16점으로써 총 24점으로 평가되었 다. 주의력 평가에는 지속 주의력, 선택 주의력, 분리 주의력, 교 대 주의력이 각 2점이며, 추론력 평가는 연역적 추론, 귀납적 추 론, 수렴적 추론, 확산적 사고가 각 4점으로 배점되어 있다.

\section{청능훈련 절차}

훈련은 1 회 50 분씩 일주일에 1회씩 총 8회에 걸쳐 실시하였 다. 훈련의 내용은 문장을 듣고 난 후 문장을 순서화하는 방법 으로 실시하였으며, 소음이 있는 상황에서 훈련이 가능한 대상 자들은 소음하에서도 실시하였다. 참여자의 평균 연령(71.7세) 을 고려하여 각 문장마다 1.5 초씩 시간 격차(pause)를 두었다. $3 \sim 5$ 개의 문장을 다 듣고 난 후 먼저 어떤 주제에 관한 이야기 인지 질문했다. 또한 수행능력에 따라 최대 2 가지의 이야기와 관련된 질문을 하였다. 이는 한 번 기억한 정보를 조작, 처리함 으로써 작업기억능력 향상을 도모하고자 하였다. 언어 과제와 밀접한 연관성을 갖는 작업기억은 단기기억(short-term memory)의 개념에서 출발하였으나 단기적 정보 유지 공간을 넘어 서 정보 처리(processing) 및 조작이 추가된 기억기제로 정의된 다(Baddeley \& Hitch, 1974). 정보를 유지하고 동시에 처리해 야 하는 고차원적 인지기제인 작업기억능력 향상을 위해 다음 과 같은 훈련 방법을 시행했다.

단서가 있는 쉬운 이야기의 예를 들어 "라면을 끓이기 위해 냄비에 물을 넣습니다. 불을 켜고 물이 끓을 때까지 기다립니 다. 물이 끓으면 면을 넣습니다. 끓는 물에 수프도 함께 넣습니 다. 면이 익었는지 확인하고 가스레인지 불을 끕니다.”와 같은 제시된 이야기를 다 들은 뒤 어그러진 문장 리스트를 보고 빈 칸에 들은 순서대로 번호를 기입할 수 있도록 하는 방식으로 진행하였다. 훈련 내용에 대한 예시는 Appendix에 제시하였다.

모든 대상자들에게 훈련 진행 시 기억력과 이야기의 이해 및 추론능력에 초점을 맞추고 소음하에서도 어음을 인지할 수 있 도록 다음의 방법을 유의하면서 실시하였다. 모든 대상자의 훈 련 콘텐츠와 방법은 동일하나 대상자들의 듣고 이해하는 수준 에 따라 어려움의 정도를 조정하였다. 예를 들어 문장의 순서 를 잘 기억하지 못하는 대상자들에게는 먼저 이야기의 주제를 질문하여 전체적인 내용을 파악하는 데 주력하게 하였다. 다음 은 다시 듣고 각 문장의 키워드를 기억하게 하고 키워드를 통하
여 문장의 순서를 기억하고 맞추는 훈련을 하였다. 이야기를 듣 고 주제를 파악하지 못하는 경우에는 들은 단어를 이야기해 보고 이야기와 관련된 간단한 질문을 통하여 대답을 유도하였 다. 이러한 훈련을 진행하는 과정에서 제대로 수행하지 못할 경 우 문장을 반복해서 듣게 한 후 문장을 보여주고 자신이 들은 단어와 문자를 매칭하는 작업을 실시하였다. 문장과 문자를 매 칭하는 작업은 수행력이 떨어지는 대상자에게만 실시하였고 최 대한 듣고 기억하고 이해하는 데 초점을 맞추어 훈련을 실시하 였다. 앞의 문장을 순서화하는 데 $80 \%$ 이상의 수행력을 보일 경 우 배경소음(white noise)을 스피커(loudspeaker)에 연결한 상태 로 SNR을 조절하며 문장을 제시하였다. 수행능력이 좋을 경우 SNR을 좀 더 낮추고, 수행능력이 좋지 못할 경우 SNR을 높이 면서 난이도를 조절하였다(Mishra \& Boddupally, 2018).

\section{통계 분석}

통계 프로그램은 SPSS 18.0(SPSS Inc., Chicago, IL, USA) 을 사용하여 분석하였다. 본 연구의 표본 크기가 작음을 고려하 여 비모수검정 분석을 실시하였고 윌콕스 부호순위검정(Wilcoxon signed rank test)을 통해 훈련 전후에 따라 훈련군과 비 훈련군으로 나누어 비교하였다. Bonferroni Type II error를 방지 하기 위하여 Adjust $p$ value를 제시하였다. 유의확률은 $p<0.05$ 인 경우 통계적으로 유의한 차이가 있는 것으로 판정하였다.

\section{RESULTS}

\section{청능훈련에 따른 소음하 어음인지력의 변화}

대상자 10 명 모두 소음이 없는 상황에서의 어음인지력, 10 $\mathrm{dB}$ SNR과 $5 \mathrm{~dB}$ SNR에서의 소음하 어음인지력이 증가하여 유의미한 차이를 보였다. 대상자 10 명의 조용한 상황에서의 어 음인지력은 평균 35.6점(표준편자: 9.69)에서 41.2(표준편차: 8.97)로 향상되었고 $10 \mathrm{~dB} \mathrm{SNR에서} \mathrm{문장인지도검사} \mathrm{결과는}$ 평균 72.5점(표준편차: 21.68)에서 78.5점(표준편차: 19.08)으로 향상되었으며, $5 \mathrm{~dB}$ SNR에서는 평균 68.7점(표준편차: 21.69) 에서 75.2점(표준편차: 19.14)으로 향상되었다. 비모수 통계분석 (Wilcoxon signed rank test)을 실시한 결과 대상자는 훈련 전 후에 소음이 없는 상황, $10 \mathrm{~dB} \mathrm{SNR,} 5 \mathrm{~dB}$ SNR의 어음인지력 이 모두 통계적으로 유의한 차이가 나타났다. 조용한 상황 속 어음인지력의 Z 값은 $-2.823(p=0.015)$ 으로, $10 \mathrm{~dB} \mathrm{SNR}$ 에서 는 $\mathrm{Z}=-2.199(p=0.028)$ 로, $5 \mathrm{~dB} \mathrm{SNR}$ 에서 $\mathrm{Z}=-2.606(p=$ 0.018)으로 모두 통계적으로 유의했다. 본 훈련 전후 증가율 비 교를 Figure 1에 제시하였다. 


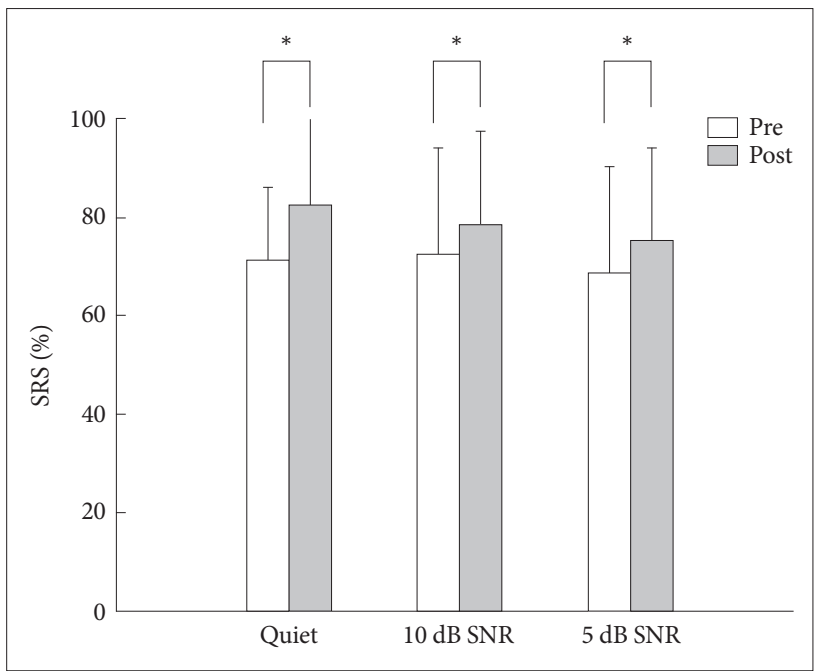

Figure 1. Sentence recognition in noise scores using Korean matrix test by pre- and post-auditory training. ${ }^{*} p<0.05$. Pre: pre-auditory training, Post: post-auditory training, SRS: sentence recognition score, SNR: signal-to-noise ratio.

\section{청능훈련에 따른 단기기억 및 작업기억력의 변화}

대상자의 훈련 전후 결과를 비교하기 위하여 비모수 통계분 석(Wilcoxon signed rank test)을 실시한 결과 훈련군에서는 훈련 전후에 통계적으로 유의미한 차이가 있었다. 단기기억력 을 평가하는 숫자 바로따라말하기검사에서 훈련군은 훈련 전 에 실시한 평가의 평균값 8.9점(표준편차: 1.37)에서 훈련 후 평 균값 9.7점(표준편차: 1.41)으로 증가하였다. 단어를 사용한 바 로따라말하기검사에서도 평균값 3.6점(표준편차: 0.96)에서 평 균값 4.5점(표준편차: 1.43)으로 증가하여 각각 $\mathrm{Z}=-2.53(p=$ $0.022), Z=-2.46(p=0.014)$ 으로 유의하게 나타났다. 작업기억 력을 평가하는 거꾸로따라말하기검사 또한 유의미한 증가가 나 타났는데, 숫자 거꾸로따라말하기검사에서는 평균값 4.8점(표 준편차: 0.91)에서 평균값 5.5점(표준편차: 0.84)으로, 단어 거꾸 로따라말하기검사에서는 평균값 4.4점(표준편차: 1.26)에서 평 균값 5.3점(표준편차: 1.15)으로 증가했다. 또한 훈련군은 각각 의 검사에서 $\mathrm{Z}=-2.64(p=0.008), \mathrm{Z}=-2.26(p=0.048)$ 으로 유의하게 나타났다. 본 훈련 전후 증가율 비교를 Figure 2에 제 시하였다.

\section{청능훈련에 따른 추론능력의 변화}

대상자의 훈련 전후 주의력검사 결과를 비교하기 위하여 비 모수 통계분석(Wilcoxon signed rank test)을 실시한 결과 통계 적으로 유의미한 차이가 나타나지 않았다. 대상자 10명의 훈련 전 추론능력검사 결과, 평균값 12.1점(표준편차: 2.33)에서 훈련 후 평균값 12.6점(표준편차: 2.27)으로 다소 증가한 점수를 보였 으나, $\mathrm{Z}=-1.89(p=0.059)$ 로 통계적으로 유의미하지 않았다.

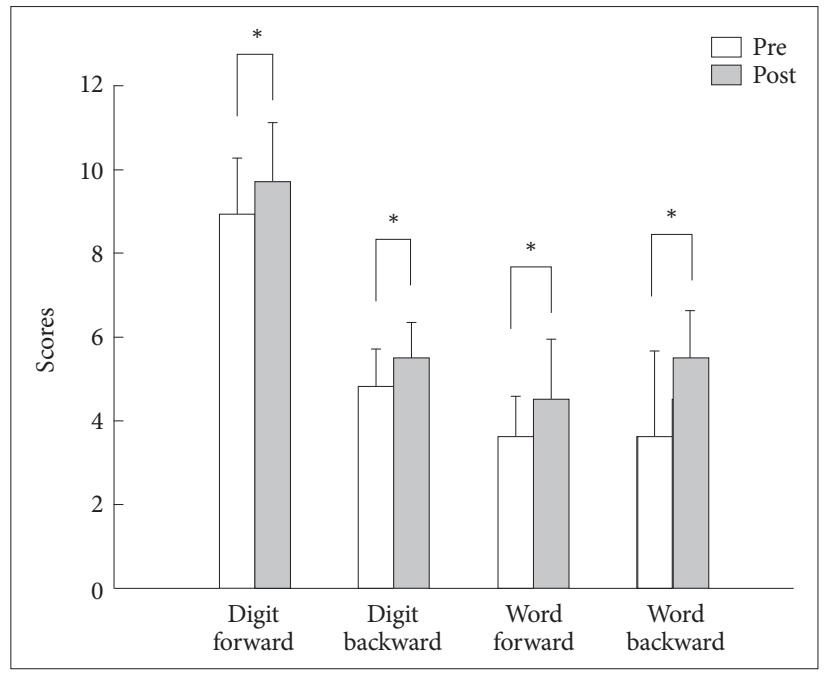

Figure 2. Sentence recognition in noise scores using Korean matrix test by pre- and post-auditory training. ${ }^{*} p<0.05$. Pre: pre-auditory training, Post: post-auditory training.

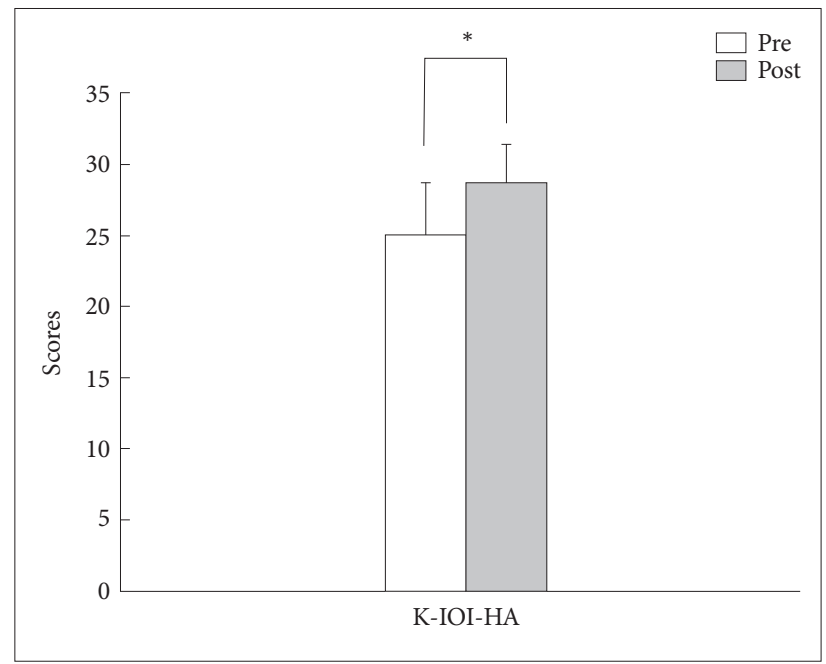

Figure 3. K-IOI-HAs scores by pre- and post-auditory training. ${ }^{*} p<$ 0.05 . Pre: pre-auditory training, Post: post-auditory training, K-IOI$\mathrm{HA}$ : Korean version of international outcome inventory for hearing aid.

\section{청능훈련 후 주관적 보청기 만족도의 변화}

대상자의 훈련 전후 Korean version of international outcome inventory for hearing aid (K-IOI-HA) 설문조사 결과 를 비교하기 위하여 비모수 통계분석(Wilcoxon signed rank test)을 실시한 결과 훈련 그룹에서 통계적으로 유의한 차이가 나타났다. $\mathrm{K}-\mathrm{IOI}-\mathrm{HA}$ 결과는 평균 25.0점(표준편차: 3.6)이 나 왔으며 8주 평가에 실시한 결과 28.7점(표준편차: 2.7)으로 증 가되었다. 통계 결과 $\mathrm{Z}=-2.816(p=0.005)$ 으로 유의하게 증가 한 것으로 나타났다. 본 훈련 전후 증가율 비교를 Figure 3에 제시하였다. 


\section{DISCUSSIONS}

본 연구는 보청기를 사용하는 노인을 대상으로 배경소음하 일련의 제시된 문장을 듣고 기억하여 순서화하는 청능훈련을 통해 소음하 어음인지력 향상뿐만 아니라 작업기억력, 추론능 력, 그리고 주관적 보청기 만족도의 향상을 보고자 하였다.

\section{소음하 어음인지력}

본 연구 결과 청능훈련 후에 소음하 어음인지능력이 향상되 어 선행논문의 결과와 일치하였다. 선행논문에서는 소음 상황 에서의 청능훈련 프로그램을 실시한 결과 대상자의 단어와 문장 의 지각능력이 모두 향상되었음을 보고하였다(Song, 2008). 또 다른 연구에서는 8주간 소음 상황에서 청능훈련을 한 결과 소음 하 단어인지도가 유의미하게 증가하였다(Kim \& Lee, 2010). Yeo et al.(2014)은 문장과 단어를 이용하여 소음하 청능훈련을 한 후 소음하 단어인지도검사(WRS)와 문장인지도검사(sentence recognition score)에서 통제 집단과 훈련 집단의 유의미한 결 과를 확인할 수 있었다. 이 외 각 연구마다 훈련 기간, 훈련 도 구, 훈련 대상자 등이 달라 직접적인 비교는 어렵지만 청능훈 련 후 소음하 어음인지력의 증가를 보였다(Fuller et al., 2018; Kim \& Lee, 2017).

\section{작업기억력 및 추론능력}

본 연구에서는 청능훈련 전후에 인지력의 향상을 확인하기 위하여 인지 영역 중 단기기억 및 작업기억력과 추론능력을 측 정하였다. 청능훈련을 통한 작업기억력의 향상의 결과는 앞선 여 러 선행연구 결과와 일치하였다. Ferguson \& Henshaw(2015)는 인지능력은 소음하 어음인지력 향상에 가장 주요한 요소이며 복잡한 언어 처리에 있어서도 인지력이 밀접하게 영향을 끼친 다고 하였다. Krishnamurti et al.(2015)에서는 경중도의 인지 장애가 있는 청력손실이 있음에도 불구하고 6 7주간의 청능훈 련이 집중력과 작업기억력의 향상을 보였다. 또한 Saunders et al.(2016)의 연구에서도 청능훈련 참여자들의 작업기억능력의 향상을 보고하였다. Anderson et al.(2013)의 연구에서는 청 능훈련을 받은 그룹의 경우 단기기억과 집중력의 증가를 보였 으나 청능훈련을 받지 않은 그룹의 경우 이러한 인지 기능의 변 화를 보이지 않았다. 훈련의 효과는 아동에게서도 볼 수 있다. Mishra \& Boddupally(2018)의 인공와우 아동 대상 결과와 일 치한다. Mishra \& Boddupally(2018)의 연구에서는 14명의 인 공와우 사용 아동에게 5 주간 순방향 숫자기억하기 훈련을, 13 명의 다른 인공와우 사용 아동에게는 역방향 숫자기억하기 훈 련을 시행하였다. 역방향 숫자기억하기 훈련을 한 13 명 아동의 경우, 훈련 후 작업기억능력이 향상되었고 훈련 후 5 주 후에도
효과가 유지되었다. 문장 작업기억능력 측정인 문장폭검사와 소음하 인지능력 간의 관계를 조사한 연구 20 개를 분석한 Ak$\operatorname{eroyd}(2008)$ 의 연구를 살펴보면 언어적 작업기억력이 소음 속 어음인지능력을 예측하는 데에 가장 강력한 요소 중 하나라고 보고하였다. 또한 Besser et al. (2013)에 따르면 작업기억력은 소음하 인지능력을 예측하는 가장 주요한 능력이라 하여 작업 기억력과 소음하 어음인지력의 증가 간의 관계가 밀접함을 알 수 있다.

본 연구에서는 인지력 중 작업기억력과 함께 추론능력을 평 가하였다. 연구 결과 훈련 전후 평균값은 소폭 상승했으나 통계 적으로 유의미한 결과가 나오지 않았다. 훈련에 사용한 재료 중 사용한 단서가 있는 문장의 경우 시간 순서 혹은 원인과 결 과 등 문장을 듣고 추론 작업을 적극적으로 하여야만 문장의 순서를 바로잡을 수 있는 작업이 필요하기 때문에 실험 전 저 자들은 추론능력의 향상을 기대하였다. 그러나 본 연구에서는 그 향상을 증명할 수 없었는데, 아마도 훈련의 재료가 추론능 력까지 향상시킬 만한 어려운 재료가 아닌 것이 원인이 될 수 있을 것이다. 난청 노인에게 있어서 단순히 문장을 순서화하는 것이 어렵지 않고 또 다른 재료인 단서가 있는 이야기의 경우 많은 추론능력이 필요한 재료가 아니기 때문이다. 다른 원인으 로는 본 연구에서 사용한 추론능력 측정을 위한 검사 도구가 본 연구에 민감하지 않은 도구였을 수 있다. 본 연구에서 추론 능력을 측정하기 위해 사용한 CAPTBI 검사는 외상성 뇌손상 (traumatic brain injury) 환자와 정상 인지능력군을 분류하는 데 높은 변별력을 지닌 검사지이다. 특히 조직화 능력, 기억력, 집행 기능 등 고차원적 인지 기능과 관련이 깊은 작업기억이 관여하는 영역들에 대한 변별력이 높아 본 연구 대상자에게 훈 련 전후로 평가를 실시했다(Lee, 2013). 후속연구로 추론능력 등의 고기능 인지능력의 향상을 요하는 훈련 도구의 개발이 필 요하겠다.

\section{보청기 주관적 만족도}

본 연구에서는 이미 보청기의 순응이 끝난 난청 노인들이 참 여하였음에도 불구하고 청능훈련 후 보청기에 대한 유의한 향 상이 있었다. 이는 Yeo et al.(2014)의 선행연구와 일치하는 결 과이다. Yeo et al.(2014)의 연구는 보청기 착용이 1년 이상이 된 대상자만이 참여하였음에도 불구하고 보청기 만족도가 유 의하게 증가함을 보고하였다. 본 연구와 Yeo et al.(2014)의 연 구를 볼 때 청능훈련은 보청기 적응이 끝난 대상자에게도 효과 가 있어 보청기를 처음 착용하는 사람들만이 청능훈련의 대상 자가 아님을 알 수 있다. 후속연구를 통하여 보청기 처음 착용 자와 순응이 끝난 대상자 중 보청기에 대한 만족도의 향상 정 도의 차이를 연구한다면 청능훈련을 행하는 효과적인 시기를 
찾을 수 있으리라 본다.

본 연구에서는 소음하에서 일련의 문장을 듣고 순서화하는 것을 목적으로 훈련을 진행하였다. 그러나 본 연구에 참여한 대상자 중 다소 높은 언어인지력을 보이는 경우 순서화하는 작 업을 많이 어려워하지 않았다. 이러한 대상자에게 보다 효과적 인 훈련을 진행하기 위해서는 좀 더 고기능 인지를 필요로 하 는 훈련 도구의 개발이 필요할 것으로 본다. 이러한 고기능 인 지를 요하는 훈련 도구를 사용할 경우 본 연구에서 유의한 증 가를 보이지 않았던 추론능력의 향상 또한 기대할 수 있을 것 이다. 또한 후속연구에서는 집중력, 집행 기능 등의 인지력 향 상을 위한 다양한 청능훈련 도구의 개발로 보청기를 착용한 노 인들이 훈련을 통해 효과적으로 인지 기능의 향상과 함께 의사 소통의 능력 향상을 높일 수 있을 것이다.

중심 단어 : 청능훈련·인지 훈련·보청기 만족도·문장 순서화· 작업기억력.

\section{Ethical Statement}

The study was approved by the Institutional Review Board of Hallym University of Graduate Studies (HUGSAUD:\# 468523).

\section{Acknowledgments}

The authors thank to the participants.

\section{Declaration of Conflicting Interests \\ There are no conflict of interests.}

\section{Funding}

This work was supported by the Ministry of Education of the Republic of Korea and the National Research Foundation of Korea (NRF2019S1A5A2A01039904).

\section{Author Contributions}

All authors contributed equally to this work. All authors interpreted and discussed the result altogether. D.K. designed the experiment, and collected and analyzed the data, and wrote the paper. S.K. and D.Y. made training materials. J.B. reviewed the final version of the manuscript.

\section{ORCID iDs}

Donghoon Kang

Junghwa Bahng

https://orcid.org/0000-0002-8538-0019 https://orcid.org/0000-0002-5265-3586

\section{REFERENCES}

Akeroyd, M. A. (2008). Are individual differences in speech reception related to individual differences in cognitive ability? A survey of twenty experimental studies with normal and hearing-impaired adults. International Journal of Audiology, 47(Sup 2), S53-S71.

Anderson, S., White-Schwoch, T., Choi, H. J., \& Kraus, N. (2013). Training changes processing of speech cues in older adults with hearing loss. Frontiers in Systems Neuroscience, 7, 97.

Baddeley, A. D. \& Hitch, G. J. (1974). Working memory. The Psychology of Learning and Motivation, 8, 47-89.

Besser, J., Koelewijn, T., Zekveld, A. A., Kramer, S. E., \& Festen, J. M. (2013). How linguistic closure and verbal working memory relate to speech recognition in noise-A review. Trends in Amplification, 17(2), 75-93.
Cai, L., Chan, J. S., Yan, J. H., \& Peng, K. (2014). Brain plasticity and motor practice in cognitive aging. Frontiers in Aging Neuroscience, 6, 31.

Ferguson, M. A. \& Henshaw, H. (2015). Auditory training can improve working memory, attention, and communication in adverse conditions for adults with hearing loss. Frontiers in Psychology, 6, 556.

Ferguson, M. A., Henshaw, H., Clark, D. P., \& Moore, D. R. (2014). Benefits of phoneme discrimination training in a randomized controlled trial of 50- to 74-year-olds with mild hearing loss. Ear and Hearing, 35(4), e110-e121.

Fuller, C. D., Galvin, J. J. 3rd., Maat, B., Başkent, D., \& Free, R. H. (2018). Comparison of two music training approaches on music and speech perception in cochlear implant users. Trends in Hearing, 22, 23312165187 65379.

Henshaw, H. \& Ferguson, M. A. (2013). Efficacy of individual computerbased auditory training for people with hearing loss: A systematic review of the evidence. PloS One, 8(5), e62836.

Jo, Y. Y., Bahng, J., \& Lee, J. H. (2013). Case study of auditory training for an elderly hearing aid user. Audiology, 9(2), 190-194.

Kang, Y., Na, D. L., \& Hahn, S. (1997). A validity study on the Korean minimental state examination (K-MMSE) in dementia patients. Journal of the Korean Neurological Association, 15(2), 300-308.

Karawani, H., Bitan, T., Attias, J., \& Banai, K. (2016). Auditory perceptual learning in adults with and without age-related hearing loss. Frontiers in Psychology, 6. 2066.

Kim, H. G. \& Lee, K. W. (2010). Effects of word recognition score as a function of auditory training terms for elderly hearing impaired with hearing aid. Audiology, 6(2), 159-163.

Kim, J. \& Lee, K. (2017). Effects on word and sentence recognition by auditory training using environmental sound for elderly hearing impaired. Audiology and Speech Research, 13(2), 115-122.

Kim, K. H. \& Lee, J. H. (2018). Evaluation of the Korean matrix sentence test: Verification of the list equivalence and the effect of word position. Audiology and Speech Research, 14(2), 100-107.

Krishnamurti, S., Tingle, D., Bannon, H., \& Armstrong, M. (2015). Role of auditory training in intervention of individuals with cognitive decline and hearing impairment. Perspectives on Gerontology, 20(2), 58-64.

Lee, M. S. (2013). Development and application of cognitive-pragmatic language ability assessment protocol for traumatic brain injury (CAPTBI) (Unpublished doctoral dissertation). Yonsei University, Seoul.

Lin, F. R. (2011). Hearing loss and cognition among older adults in the United States. The Journals of Gerontology, Series A: Biological Sciences and Medical Sciences, 66A(10), 1131-1136.

Mener, D. J., Betz, J., Genther, D. J., Chen, D., \& Lin, F. R. (2013). Hearing loss and depression in older adults. Journal of American Geriatrics Society, 61(9), 1627-1629.

Mishra, S. K. \& Boddupally, S. P. (2018). Auditory cognitive training for pediatric cochlear implant recipients. Ear and Hearing, 39(1), 48-59.

Nuesse, T., Steenken, R., Neher, T., \& Holube, I. (2018). Exploring the link between cogntivie abilities and speech recognition in the elderly under different listening conditions. Frontiers in Psychology, 9, 678.

Pichora-Fuller, M. K., Schneider, B. A., \& Daneman, M. (1995). How young and old adults listen to and remember speech in noise. The Journal of the Acoustical Society of America, 97(1), 593-608.

Roque, L., Karawani, H., Gordon-Salant, S., \& Anderson, S. (2019). Effects of age, cognition, and neural encoding on the perception of temporal speech cues. Frontiers in Neuroscience, 13, 749.

Saunders, G. H., Smith, S. L., Chisolm, T. H., Frederick, M. T., McArdle, R. A., \& Wilson, R. H. (2016). A randomized control trial: Supplementing hearing aid use with listening and communication enhancement (LACE) auditory training. Ear and Hearing, 37(4), 381-396.

Schow, R. L. \& Nerbonne, M. A. (2006). Introduction to Audiologic Rehabilitation. Boston, MA: Pearson Education.

Song, S. M. (2008). The effect of speech In noise training on the speech perception of cochlear implanted adults (Unpublished master's thesis). Daegu University, Daegu. 
Sung, J. E. (2011). The reliability and validity of short-term and working memory pointing tasks developed for clinical populations with speech and language disorders. Communication Sciences and Disorders, 16(2), 185-201.

Sweetow, R. W. \& Sabes, J. H. (2006). The need for and development of an adaptive Listening and Communication Enhancement (LACE) program. Journal of the American Academy of Audiology, 17(8), 538-558.

Tremblay, K. L. (2007). Training-related changes in the brain: Evidence from human auditory-evoked potentials. Seminars in Hearing, 28(2), 120-132.

Wall, J. T., Xu, J., \& Wang, X. (2002). Human brain plasticity: An emerging view of the multiple substrates and mechanisms that cause cortical changes and related sensory dysfunctions after injuries of sensory inputs from the body. Brain Research Reviews, 39(2-3), 181-215.

World Health Organization. (2020, March 1). Deafness and Hearing Loss. World Health Organization. Retrieved from https://www.who.int/en/ news-room/fact-sheets/detail/deafness-and-hearing-loss.

Wolfgang, K. (2019). Hearing loss and dementia: Breakthrough research seeks causal link. The Hearing Journal, 72(9), 22-23, 26.

Yeo, S., Bahng, J., \& Lee, J. H. (2014). Efficacy of auditory training using sentences in noise for hearing aid users. Audiology, 10(1), 65-75. 
APPENDIX

\section{Example of the Training Session}

\begin{tabular}{|c|c|c|c|}
\hline & 훈련 내용 & 훈련 목표 & 비 \\
\hline 상담(10분) & $\begin{array}{l}\text { () 인사(안부, 문제점 파악) } \\
\text { () 보청기 상태 점검-육안으로 점검하고 } \\
\text { 소리 질과 볼륨 상태를 점검함 }\end{array}$ & & $\begin{array}{l}\text { 훈련 전 보청기 점검 } \\
\text { - 문제가 있는 경우 적합 상태를 확인 } \\
\text { 하여 문제를 해결하고 훈련을 실시 } \\
\quad \text { 한다. }\end{array}$ \\
\hline 훈련(30분) & $\begin{array}{l}\text { (0) } 6 \mathrm{~dB} \text { SNR } \\
\text { - 단서가 있는 이야기 } 5 \text { 세트(3문장 2세트, } \\
\text { 4문장 2세트, } 5 \text { 문장 } 1 \text { 세트) } \\
\text { - 단서가 없는 이야기 } 5 \text { 세트(3문장 2세트, } \\
\text { 4문장 } 2 \text { 세트, } 5 \text { 문장 } 1 \text { 세트) } \\
\text { (0) } 3 \mathrm{~dB} \mathrm{SNR} \\
\text { - 단서가 있는 이야기 } 5 \text { 세트(3문장 2세트, } \\
\text { 4문장 } 2 \text { 세트, } 5 \text { 문장 } 1 \text { 세트) } \\
\text { - 단서가 없는 이야기 } 5 \text { 세트(3문장 2세트, } \\
\text { 4문장 } 2 \text { 세트, } 5 \text { 문장 } 1 \text { 세트) }\end{array}$ & $\begin{array}{l}\text { 각 조건에서 2번까지 } \\
\text { 반복하여 듣고 } 80 \% \\
\text { 이상의 수행력을 목표로 } \\
\text { 한다 }\end{array}$ & $\begin{array}{l}\text { 수행력의 난이도 조절 } \\
\text { - 소음 대 잡음비를 조정하도록 함 } \\
\text { 소음하에서 수행하지 못하는 경우 } \\
\text { - 소음이 없는 환경에서 훈련을 실시 } \\
\quad \text { 하도록 함 }\end{array}$ \\
\hline 마무리(5분) & $\begin{array}{l}\text { () 실시한 훈련과 수행력에 관하여 간단한 } \\
\text { 상담(다음 훈련 계획 설명) } \\
\text { () 대상자가 궁금해하는 사항에 대하여 } \\
\text { 질문하고 답함 } \\
\text { () 일상생활에서의 듣기 활동에 대한 조언 }\end{array}$ & & \\
\hline
\end{tabular}

SNR: signal-to-noise ratio 